\title{
DIVERSIDAD GENÉTICA DE POBLACIONES DE AJO (Allium sativum L.) CULTIVADAS EN GUATEMALA, DEFINIDA POR MARCADORES DE ADN1
}

\author{
Fredy Uber Rosales-Longo ${ }^{2}$, Luis Gerardo Molina-Monterroso ${ }^{3}$
}

\begin{abstract}
RESUMEN
Diversidad genética de las poblaciones de ajo (Allium sativum L.) cultivadas en Guatemala, definida por marcadores de ADN. En Guatemala es escasa la información sobre la diversidad genética de ajo. Los objetivos del estudio fueron: incidir en el mejoramiento de Allium sativum, sobre la base del conocimiento de su variabilidad genética, así mismo, establecer una colección in vitro de la colección de las poblaciones cultivadas en Guatemala. Los experimentos fueron realizados entre octubre de 2005 y marzo de 2006. La determinación de las variaciones de ADN se realizaron mediante la técnica de AFLP ${ }^{\mathrm{TM}}$. La información se analiza por medio de análisis de componentes principales, análisis de coordenadas principales y análisis de conglomerados. Mediante la inspección de los productos de AFLP ${ }^{\text {тм }}$ у análisis estadísticos, se detectó una alta variabilidad genética entre los materiales vegetales colectados. Las muestras clasificadas como del tipo "Chileno", correspondieron a los tipos "Criollo". Nueve bien diferenciados grupos genéticos se conformaron en un dendrograma y se confirmó que la diversidad genética descubierta es una función del lugar donde se cultivan las poblaciones de ajo. Se identificó una mayor diversidad genética entre las muestras de ajo del tipo "Criollo" que las que se tienen entre los materiales del tipo "Chileno", como producto de la mayor dispersión espacial de los primeros. Los materiales genéticos de ajo se encuentran actualmente preservados en un Banco de Germoplasma in vitro en la Unidad de Biotecnología del ICTA.
\end{abstract}

Palabras clave: Ajo, diversidad genética, mejoramiento genético, AFLP ${ }^{\text {тм }}$, PCA, lluster análisis.

\begin{abstract}
Genetic diversity of the garlic (Allium sativum L.) grown in Guatemala, revealed by DNA markers. Before this research was done, the information about genetic variability of the garlic (Allium sativum L.) cultivated populations, was insufficient in Guatemala. The main objectives of this study were to contribute to the techological development of A. sativum breeding on the basis of the knowledge of its genetic variability. This study was carried out between October 2005 and March 2006. The determination of the DNA variation was done by AFLP technique. Data were analyzed by Principal Coordinate, Cluster and Allele Diversity analyses. By AFLP ${ }^{\mathrm{TM}}$ technique and statistical analysis, a high genetic variability was detected among the collected plant materials. It was found by Cluster and Principal Coordinates Analysis that many of the samples of "Chilean" type are actually in the same group of the "Criollo" type; consequently, those samples should be classified as Criollo type. Nine well differentiated genetic groups were conformed and it was confirmed that the genetic variability is a function of the site where garlic is grown. Higher genetic diversity was found among the "Criollo" samples in comparison with the diversity observed within the "Chilean" samples. Garlic plant genetic materials are now preserved at in vitro Germplasm Collection Bank at the ICTA's Biotechnology Unit.
\end{abstract}

Key words: Garlic, genetic diversity, plant breeding, $\mathrm{AFLP}^{\mathrm{TM}}$, PCA, cluster analysis.

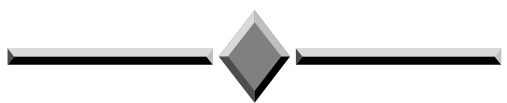

\footnotetext{
1 Recibido: 16 de junio, 2006. Aceptado: 5 de marzo, 2007. Actividad del proyecto AGROCYT 036-2002: Estudio de la variabilidad genética de Allium sativum L. cultivado en Guatemala y formación de un banco in vitro de germoplasma representativo.

2 Unidad de Biotecnología, Instituto de Ciencia y Tecnología Agrícolas. Labor Ovalle, Quetzaltenango, Guatemala, C.A. Correo electrónico: flongo@catie.ac.cr

3 Unidad de Biotecnología, Instituto de Ciencia y Tecnología Agrícolas. Bárcena, Villa Nueva, Guatemala, C.A. Correo electrónico: biotecnología@icta.gob.gt
} 


\section{INTRODUCCIÓN}

Las plantas de ajo (Allium sativum L.), son apomícticas obligadas (Novák et al. 1982) y se propagan a través de bulbos (gajos o dientes), exhiben variación morfológica entre las distintas poblaciones.

A. sativum se clasifica en dos variedades ophioscorodon y sativum. La variedad A. sativum var. ophioscorodon (Hard neck), es reconocido por la producción de un escapo floral que produce al final una umbela estéril, en tanto que A. sativum var. sativum no produce tal escapo floral en condiciones normales y es conocido como ajo de cuello blando (soft neck) (Engeland, citado por Al-Zahim et al. 1997). En Guatemala las poblaciones de ajo cultivadas corresponden a A. sativum var. ophioscorodon.

El ajo producido en Guatemala no reúne las calidades demandadas en el mercado internacional, principalmente en lo referente al número de gajos y diámetro ecuatorial (Rosales-Longo 1999). El ajo cultivado en Guatemala posee características agronómicas deseables como: un ciclo corto (120 días) y resistencia a algunas enfermedades fungosas. El desarrollo de materiales genéticos con propiedades adecuadas para los mercados internacionales contribuirá al mejoramiento de la competitividad del producto.

El sector agrícola en el campo de la producción de ajo, podrá contar en un plazo razonable con materiales genéticos de ajo que permitan a los productores reposicionar sus condiciones como productores así como mejoras en las diferencias entre costos y ganancias. La diversidad genética del ajo actualmente no es conocida y se estima que cuenta con variaciones que pueden ser explotadas para el mejoramiento genético de la especie, mediante técnicas no convencionales. La información sobre la diversidad genética del ajo cultivado es necesaria para el establecimiento de un programa de mejoramiento genético. Actualmente en Guatemala se consume ajo producido en China y que supera las calidades del ajo producido localmente, con diámetros de bulbo de hasta $60 \mathrm{~mm}$, en tanto que los productores, en el promedio, producen ajos con diámetros inferiores a 40 mm y con más de 25 gajos por bulbo (Rosales-Longo
1999). El objetivo de este trabajo fue identificar variabilidad genotípica de las poblaciones de ajo cultivado en Guatemala, mediante la aplicación de la técnica de AFLP ${ }^{\text {тм }}$ (Vos et al. 1995), que es además es de utilidad para la identificación de regiones asociadas a características de interés (Guzmán-Maldonado et al. 2003).

\section{MATERIALES Y MÉTODOS}

El trabajo se condujo en el período de marzo de 2005 a enero de 2006 en los invernaderos y laboratorios del Instituto de Ciencia y Tecnología Agrícolas (ICTA), ubicados en los departamentos de Quetzaltenango y Guatemala.

Material vegetal. Se utilizaron hojas frescas y bulbos de 71 muestras ( 71 colectas de campo) regeneradas en un invernadero. De éstas, 43 estaban etiquetadas como del tipo "chileno", 27 del tipo "Criollo" y una muestra de ajo tipo "Taiwanés", la variedad ICTASELEGUA. Las muestras fueron colectadas en fincas de productores en dos municipios del departamento de Huehuetenango: Aguacatán y Chiantla y dos municipios del departamento de Quiché: Sacapulas y Cunén.

Se empleó la técnica de Muestreo Aleatorio Estratificado (Sheaffer et al. 1986). El tamaño de la muestra se determinó mediante la siguiente ecuación:

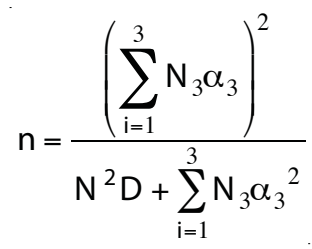

$\mathrm{n}=$ Tamaño de la muestra.

$\mathrm{i}=$ Número de estratos, cuatro estratos, estos corresponden a las áreas de cultivo en los municipios sujetos de muestreo.

$\mathrm{N}=$ Total de productores en cultivo a inicios del 2001 por municipio.

$\alpha=$ Desviación estándar, se calculó sobre la base 
de una inspección de la variabilidad en cuanto al tamaño promedio del área sembrada por un grupo de 15 productores en cada municipio. Este "premuestreo" con base en el tamaño del área sembrada se realizó únicamente para el cálculo del tamaño de la muestra y no posee ninguna implicación específica o determinante en los procedimientos propios del muestreo.

El error de estimación se estableció sobre la base del premuestreo en cuanto al tamaño de las parcelas sembradas. Se realizó esta estimación con los datos provenientes del premuestreo. La estrategia de "alocación" fue proporcional, en función del número de productores que se estimó se ubican en cada municipio.

Obtención de ADN genómico total, por medio de la metodología CTAB (Wilkie 1997; Sambrook y Russell 2001). Se utilizó material vegetal proveniente de bulbos cultivados en invernadero $(0,2 \mathrm{~g})$, de muestras de ajo cultivado en 71 fincas de productores en Guatemala en los departamentos de Huehuetenango y Quiché. Las muestras se congelaron en nitrógeno líquido y se maceraron con mortero y pistilo. El macerado se trasladó a cuatro tubos Eppendorf y se le agregó a cada uno 0,6 ml de buffer "lysis" y $200 \mathrm{ml}$ de buffer CTAB. Se realizó posteriormente una incubación del ADN y precipitación del mismo con etanol frío, y un secado del "pellet". Finalmente, el ADN fue resuspendido en $100 \mathrm{ml}$ de TE incubando la solución a $65^{\circ} \mathrm{C}$ durante $10 \mathrm{~min}$. El ARN fue extraído mediante la adición a cada tubo de $0,15 \mathrm{mg}$ de Ribonucleasa A e incubando a $37^{\circ} \mathrm{C}$ durante $40 \mathrm{~min}$. Posteriormente, se agregó 0,2 mg de Proteinasa K y se incubó la solución a $50^{\circ} \mathrm{C}$ durante $20 \mathrm{~min}$. Todas las fracciones se colocaron en un mismo tubo y el ADN fue extraído mediante fenolización y centrifugado como se describió anteriormente. El ADN se precipitó con etanol en 1/10 de volumen de acetato de sodio $3 \mathrm{M}$ durante una hora a $-20^{\circ} \mathrm{C}$. Luego de lavarse con etanol $70 \%$, el ADN se centrifugó, y finalmente, se resuspendió en 50 $\mathrm{ml}$ de agua doblemente destilada.

Estimación de la concentración total de ADN. Mediante el uso de un espectrofotómetro marca BIO RAD, Modelo Smartec 3000 se determinaron las concentraciones de ADN obtenidas y su pureza. Adicional- mente se hicieron electroforesis en geles de agarosa con el mismo fin de evaluar la concentración y la pureza del ADN.

Marcadores AFLP ${ }^{\mathrm{TM}}$ y amplificación por PCR. Por su consistencia en la amplificación y los niveles de polimorfismos, se eligieron cuatro combinaciones de imprimadores de 64 posibles combinaciones, con los cuales se generaron 332 polimorfismos. Estas combinaciones de imprimadores fueron $\mathrm{E}+\mathrm{ACC} /$ $\mathrm{M}+\mathrm{CAC}, \mathrm{E}+\mathrm{ACG} / \mathrm{M}+\mathrm{CAA}, \mathrm{E}+\mathrm{AGG} / \mathrm{M}+\mathrm{CTG}, \mathrm{E}+\mathrm{A}-$ $\mathrm{CA} / \mathrm{M}+\mathrm{CAC}$. ( $\mathrm{E}=$ Secuencia de corte para ECO-RI, $\mathrm{M}=$ Secuencia de corte para MSE- I). Las amplificaciones por PCR fueron conducidas en un volumen de $10 \mu \mathrm{L}$, conteniendo $0,25 \mathrm{ng} / \mu \mathrm{L}$ de ADN genómico. Todas las reacciones de PCR contuvieron $0,025 \mathrm{U} / \mu \mathrm{L}$ de Amplitaq (Applied Biosystems, Inc.) 0,2mM de dNTPs, 0,25 $\mu \mathrm{M}$ de cada juego de imprimadores, PCR buffer (1,5 mM MgCl2, $10 \mathrm{mM}$ Tris- $\mathrm{HCl} \mathrm{pH} 8,0 ; 50$ $\mathrm{mM} \mathrm{KCl} \mathrm{0,001 \%} \mathrm{w/v).} \mathrm{El} \mathrm{programa} \mathrm{para} \mathrm{la} \mathrm{PCR} \mathrm{fue}$ el siguiente: cuatro minutos de desnaturalización a $94^{\circ} \mathrm{C}$; un minuto de alineamiento a $55^{\circ} \mathrm{C}$; un minuto de extensión a $72^{\circ} \mathrm{C}$ este programa se repitió por 35 ocasiones. Las muestras se conservaron finalmente a $4^{\circ} \mathrm{C}$.

Electroforesis. Los productos de AFLP ${ }^{\mathrm{TM}}$ se separaron en geles de acrilamida 5,8 \%. El gel se precalentó a $50^{\circ} \mathrm{C}$ y se cargaron $5 \mu \mathrm{L}$ de muestra para una corrida a 70-80 W (1700-1800 V) en TBE $1 \mathrm{X}$ en un sistema de electroforesis vertical. Después de la electroforesis se realizaron las tinciones de las bandas con Nitrato de Plata y posteriormente se revelaron.

Análisis de la información. Con la matriz de ausencias/presencias construida a partir de los patrones de bandas en los geles de poliacrilamida (Figura 1), se construyó una matriz de similitudes por el método de DICE (2a/(2a+b+c)) (Dice 1945; Nei y Li 1979). Con estos valores se realizaron análisis de coordenadas principales (ACP) (Gower 1966), y análisis de conglomerados (cluster análisis) con el programa para computadora NTSYSpc Versión 2.02c. Este análisis se utilizó para representar las relaciones entre las poblaciones en estudio, para esto se construyó un dendrograma con la metodología "secuencial, aglomerativo, jerárquico y anidado" cluster análisis (SAHN, siglas en inglés) (Sneath y Sokal 1973; Sokal y Rohlf 1998). 


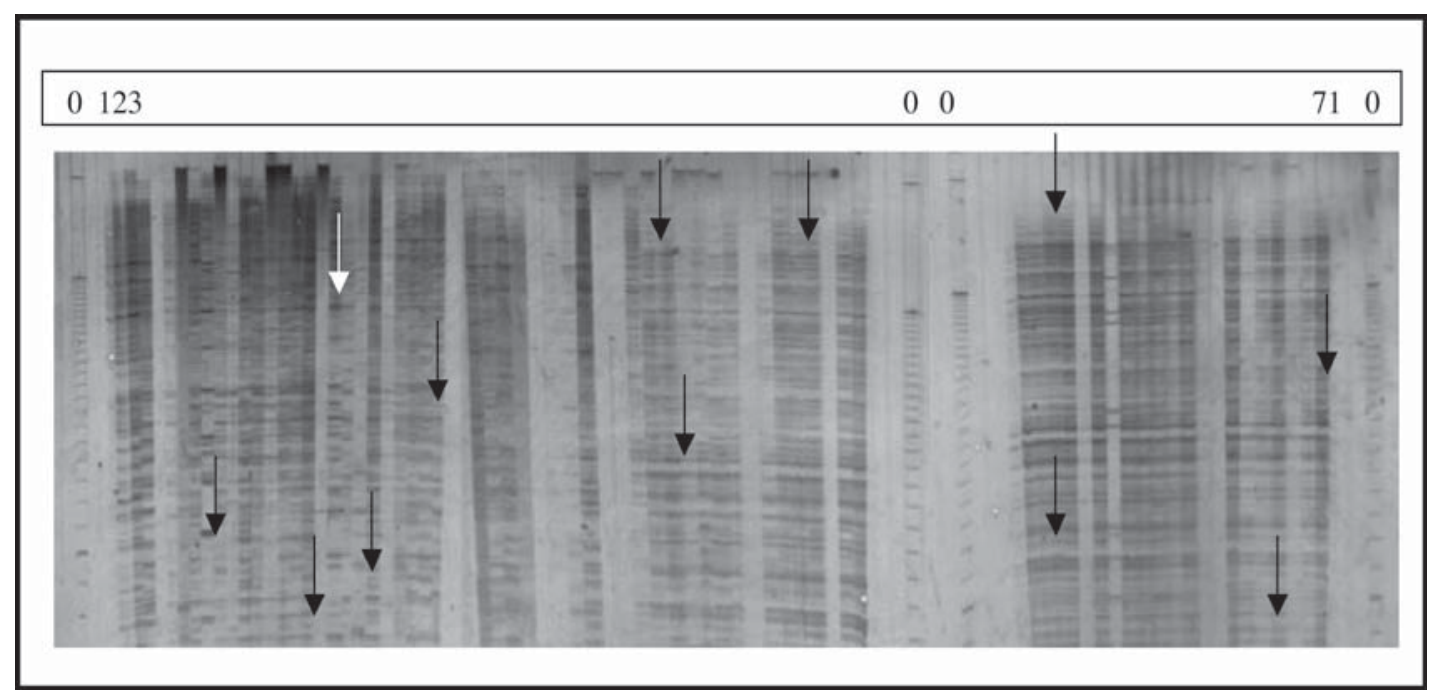

Figura 1. Imagen de un "gel" de poliacrilamida con parte de los polimorfismos encontrados. ( $0=$ marcador de peso molecular. Se muestran la indicación desde la primera hasta la muestra \# 71). Guatemala, marzo, 2006.

\section{RESULTADOS Y DISCUSIÓN}

Se extrajeron y purificaron cantidades de ADN cercanas a $200 \mathrm{ng} / \mu \mathrm{l}$ en la muestras de ajo. En la Figura 2 se observa que el ADN extraído de hojas tiende a contaminarse y a degenerarse mucho, más que la que proviene de bulbos. Además, también se puede apreciar que el ADN extraído de hojas se estima mayor degradación, lo cual se identifica por un barrido desde la banda principal ubicada al inicio en la parte superior para cada carril. Debido a que en las hojas ocurre una más rápida degradación de los tejidos, lo cual promueve la oxidación y formación de fenoles, que contaminan las muestras de $\mathrm{ADN}$, lo anterior se refleja finalmente en los "barridos" que se observan en los geles de electroforesis.
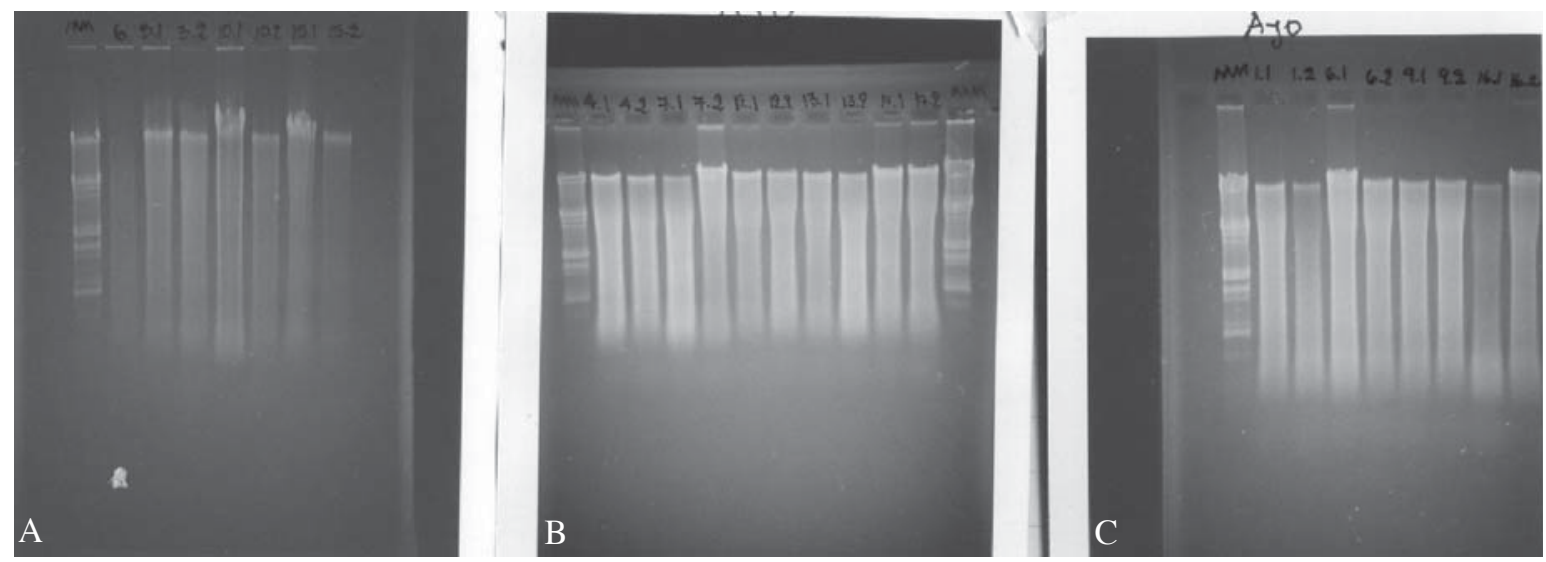

Figura 2. Integridad del ADN. a. ADN extraído de bulbos de ajo. b y c Imágenes que corresponden a ADN extraído de hojas. Guatemala, marzo, 2006. 
Las combinaciones de imprimadores que ofrecieron los mejores resultados en cuanto a un mayor número de polimorfismos obtenidos son las que se presentan en el Cuadro 1.

Cuadro 1. Combinaciones utilizadas como "imprimadores" para la amplificación de polimorfismos de ADN de ajo para el análisis de AFLP ${ }^{\mathrm{TM}}$. Guatemala, marzo, 2006.

\begin{tabular}{cc}
\hline & Combinación de Imprimadores $^{\mathbf{1}}$ \\
\hline 1 & $\mathrm{E}+\mathrm{ACC} / \mathrm{M}+\mathrm{CAC}$ \\
2 & $\mathrm{E}+\mathrm{ACG} / \mathrm{M}+\mathrm{CAA}$ \\
3 & $\mathrm{E}+\mathrm{AGG} / \mathrm{M}+\mathrm{CTG}$ \\
4 & $\mathrm{E}+\mathrm{ACA} / \mathrm{M}+\mathrm{CAC}$ \\
\hline
\end{tabular}

1 E: ECO R-I. M: MSE-I Corresponden A las secuencias de bases en donde realizan el corte del ADN las enzimas Eco RI; MSE-I, más las bases sugeridas. ( $\mathrm{A}=\mathrm{Adenina}, \mathrm{T}=\mathrm{Timina}$, $\mathrm{G}=$ Guanina, $\mathrm{C}=$ Citosina $)$.

El ADN aislado de 71 muestras se analizó por la técnica de AFLPTM (Vos et al. 1995). En la Figura 1 se presenta una imagen de tres de los doce geles realizados para la separación de bandas de ADN para los marcadores de AFLP ${ }^{\mathrm{TM}}$.

En la Figura 1 se exhibe una fotografía de tres "geles" donde se muestran los polimorfismos encontrados para la primera combinación de imprimadores E +
ACC/ M + CAC. Se detectó un alto nivel de polimorfismos (algunos mostrados por flechas en la Figura 1) para la diferenciación de las muestras en estudio, se esperaba que las diferencias genéticas no fueran tan marcadas, debido a que se trata de una especie apomíctica obligada y exige reproducción clonal desde hace aproximadamente 5.000 años (Herklots 1972).

El ajo es una especie completamente domesticada y en consecuencia se presume de altos niveles de uniformidad genética. Las primeras tres coordenadas principales explican el $28 \%$ del total de la variabilidad detectada entre las 71 muestras en estudio para un total de 332 polimorfismos. Este es un valor bastante bueno para poder explicar la ordenación de la variabilidad en las primeras tres coordenadas principales (Figura 3 ), este método se ha utilizado en otras especies para detectar la diversidad genética genética vegetal (Schnell et al. 2003).

Se aprecia en la Figura 3 dos imágenes de la misma ordenación, éstas se presentan en dos ángulos diferentes. Los patrones de dispersión de los tipos "chilenos" y "criollos" son diferentes en el espacio. Esta es una evidencia de que las variabilidades exhibidas por ambos tipos pueda deberse a diferencias en los criterios de selección por parte de los productores, o bien, a diferencias genéticas muy marcadas. También podría ser indicativo de las estrategias de mejora genética. Se ha descubierto una variabilidad significativa entre las muestras analizadas, lo cual permite una adecuada
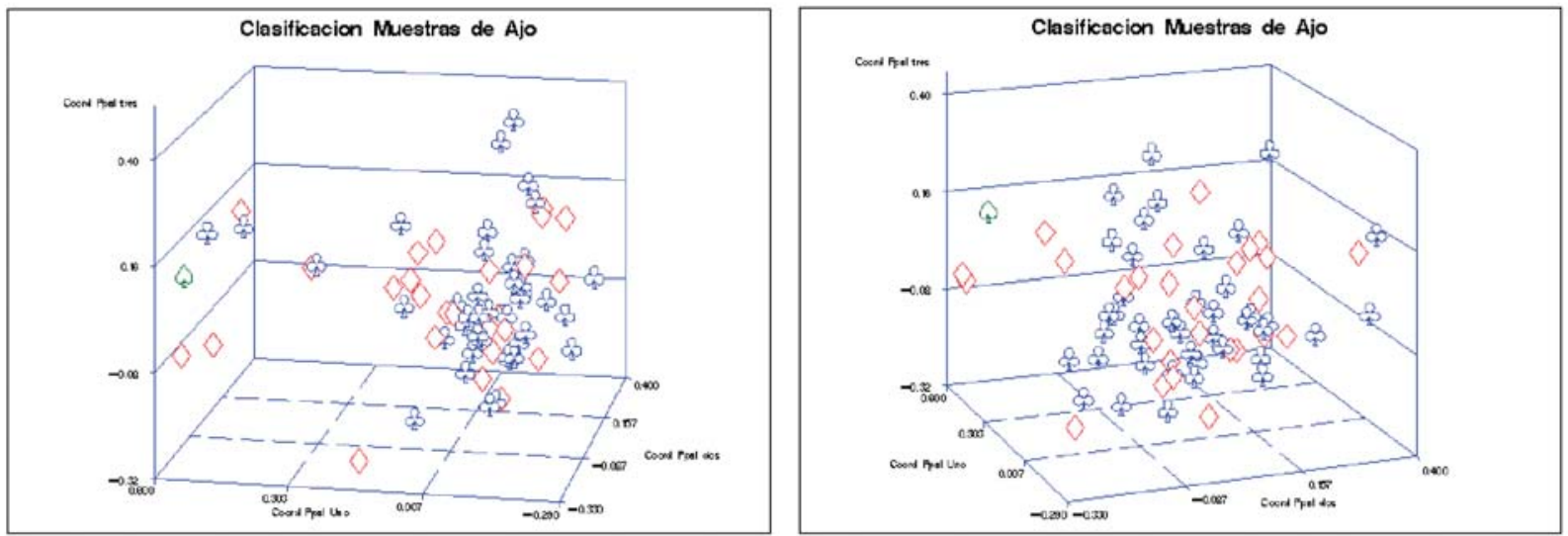

Figura 3. Análisis de coordenadas principales (PCA) para la evaluación del germoplasma de ajo por AFLP ${ }^{\text {Tм }}$ \& Tipo Chileno. Tipo Criollo. ^ Tipo Taiwanés.Se trata de la misma gráfica, en dos ángulos diferentes de observación. Guatemal, marzo, 2006. 
identificación de los cultivares, así como la posibilidad de realizar mejoramiento genético no convencional o bien el empleo de técnicas moleculares para asistir el mejoramiento genético (Chen et al. 2003). Los niveles de variabilidad entre grupos taxonómicos ha sido estudiada por Al-Zahim et al. (1997) quienes reportan variabilidad genética entre grupos taxonómicos, mediante el uso de RAPD's (Phillips et al. 1995); sin embargo, estos autores no encontraron variabilidad dentro de los grupos taxonómicos estudiados.

La muestra del tipo taiwanés se aísla en un solo grupo muy bien diferenciado. Lo anterior es natural, este tipo de ajo corresponde a Allium sativum var. sativum en tanto que tipos "chileno" y "criollo" corresponden a Allium sativum var. ophioscorodon. Se demuestra que los grupos "chileno" y "criollo" conservan mucha similitud, entre ellos, y se nota que varias de las muestras reconocidas como del tipo "chileno", en realidad corresponden a ajo del tipo "criollo". Se explica porque los productores tienden a mezclar las semillas de estos dos tipos y a nombrarlos como "chileno", pues el precio de este tipo en el mercado es superior al del tipo "criollo".

Se aprecia una tendencia de agrupamiento de las muestras hacia el centro a lo largo de la coordenada principal dos, y hacia la derecha a lo largo de la coordenada principal uno, en especial de las muestras del tipo "chileno" (Figura 1). Adicionalmente, puede observarse que las muestras de tipo "criollo" se agrupan en su mayoría hacia la derecha de la coordenada principal uno, pero son más dispersos a lo largo de la coordenada principal dos. Por esto, los tipos "criollo" tienen un mayor nivel de dispersión que los "chilenos", y esto es una indicación de la mayor diversidad genética que se encuentra entre estos materiales vegetales. Es importante señalar que existen muestras de estos dos materiales ("chilenos" y "criollos") que se separan notablemente del resto. Estos materiales presentan una mayor diferenciación genética que serviría para la conformación de una colección núcleo.

Con respecto a la ordenación de los materiales a lo largo de la coordenada principal tres, se puede decir que los tipos "chilenos" muestran mayor dispersión. Los tipos "criollos" presentan un patrón de distribución diferente, y la dispersión es a lo largo del eje de coordenada principal dos. Esta es una forma correcta de visualizar la dispersión y decidir la separación de las muestras para la formación de la colección núcleo. Así, las muestras que se encuentran más alejadas en cada eje deben separarse como muestras diferenciadas genéticamente, en tanto que aquellas que se aglomeran hacia un punto en articular debieran considerarse esencialmente el mismo material genético.

La Figura 4 presenta valores del coeficiente de UPGMA (método de agrupamiento por pares por el promedio aritmético no ponderado, siglas en inglés) que fue el método de agrupación. En la Figura 4 se observa la estructura de las poblaciones; en primer lugar, es claro que se aprecia la formación de dos grupos bien diferenciados entre sí. El primer grupo se forma por dos muestras: la VGA-03-040 y la VGA-03-051 (para efectos de simplicidad en adelante solamente se consignarán el número de orden que es el último número del código), las cuales forman un solo grupo genético. A pesar de formar un solo grupo genético, estas mantienen una distancia considerable entre sí (son similares entre sí en apenas cerca del 16\%), lo cual explica que ambos no se encuentren cercanos en la distribución que se presenta en la Figura 3. Estos dos materiales pertenecen a dos grupos diferentes según la referencia original del productor. La muestra 40 corresponde al tipo criollo y la 51 al tipo chileno. Por coincidencias genéticas, estos dos materiales corresponden en realidad al tipo criollo. En todo caso es preciso anotar que estos dos materiales genéticos, son diferentes al resto de las muestras cerca de un $96 \%$.

El resto de las observaciones se agrupan en un solo grupo, si bien la similitud global entre éstas es de cerca del $12 \%$. En lo sucesivo para un análisis de conglomerados, se forman varios grupos en un orden generalizado por la metodología de (SAHN) (secuencial, aglomerativo, jerárquico y anidado, siglas en inglés). Se detectó alta variabilidad genotípica entre los materiales colectados. Según el dendograma, se conformaron nueve grupos genéticos. Se observa que la agrupación de los materiales estuvo relacionada con el lugar donde se cultivan. En el primer conglomerado (de arriba hacia abajo) se agrupan aquellos materiales genéticos que provienen de las localidades de Sacapulas y Cunen en el departamento de El Quiché. En el siguiente grupo dos materiales de Cunen están relacionados con 


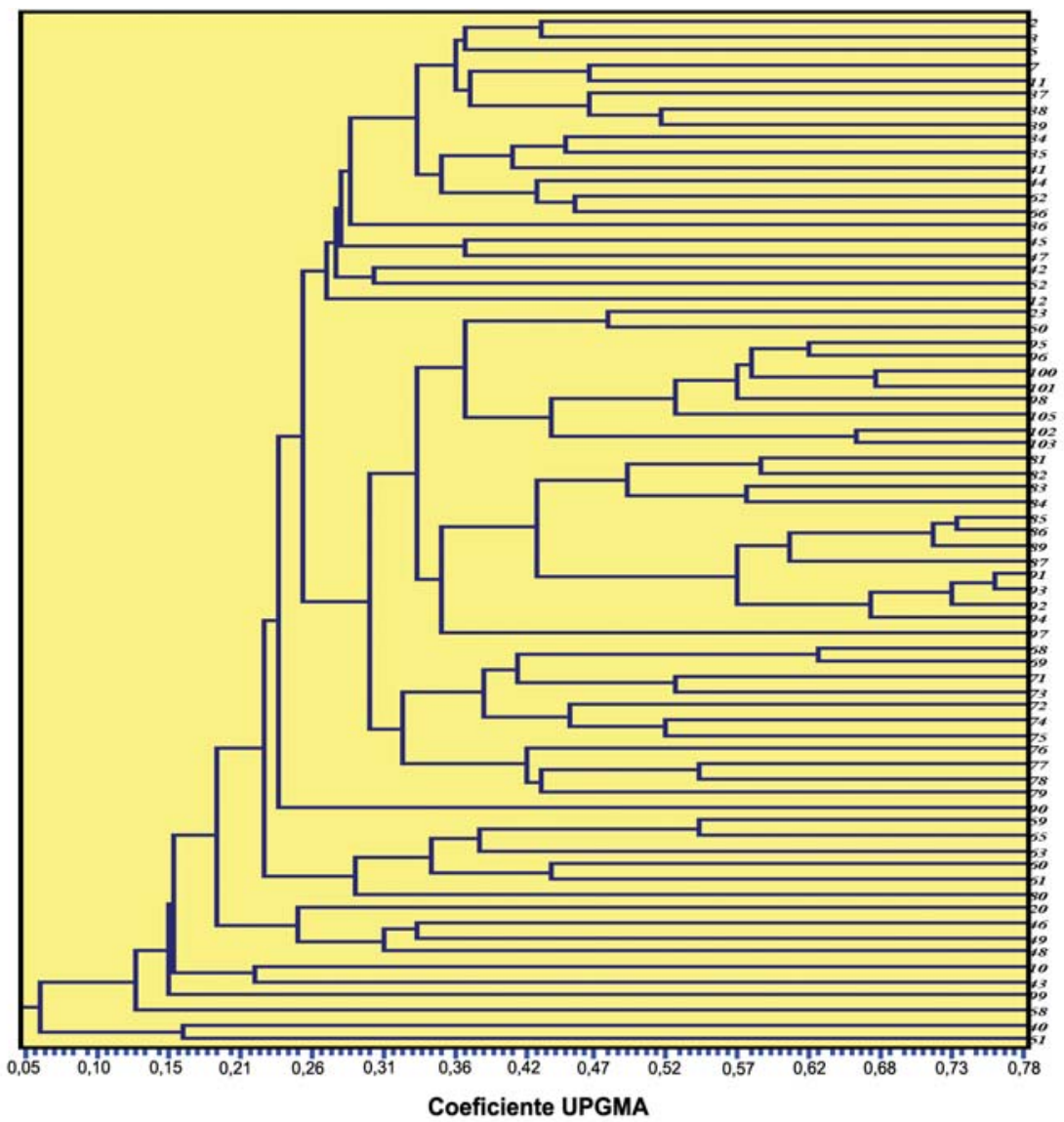

Figura 4. Dendrograma elaborado a partir de una matriz de distancias por el método de DICE, derivada a su vez de una matriz rectangular de ausencias y presencias obtenida de los marcadores AFLP ${ }^{\mathrm{TM}}$. Guatemal, marzo, 2006.

algunos colectados en Aguacatán. Los materiales 95, 96, 98 se relacionan entre sí, y provienen del municipio de Chiantla en Huehuetenango, tienen cierta relación (30\%) con algunos materiales genéticos provenientes de Sacapulas. En los años 1996 al 1998, productores de Chiantla estuvieron comprando ajo proveniente de la comunidad de Parraxtut en Sacapulas Quiché, para ser empleada como semilla en Chiantla, es posible entonces que se trate de los mismos materiales genéticos.

Los materiales genéticos $81,82,83,84,85,86$, $87,89,91,92,93$ y 94, provienen de Chiantla en Huehuetenango, y corresponden a un mismo conglomerado que los agrupa con 57\% aprox. de semejanza. Se trata de materiales genéticos que corresponden al tipo Criollo. Se nota que la selección de los materiales genéticos varía de un grupo de productores a otro. Las cuatro regiones que fueron sujetas de muestreo, varían en aspectos culturales, particularmente el lenguaje.

El siguiente grupo genético, las muestras 68,69 , $71,72,73,74,75,76,77,78$ tuvo una similitud general entre éstos del $30 \%$. Todas las muestras provienen de la aldea los Regadíos Chiantla. Es claro que los tipos de ajo son producto de la selección por parte de los productores, y que los criterios de selección están concatenados con formas culturales generalizadas para comunidades específicas.

El siguiente grupo proviene de dos municipios diferentes, pero sobre la misma ruta de comunicación. Los genotipos colectados en Aguacatán también 
presentan un patrón de agrupamiento que tiende a unir estos genotipos en el mismo grupo de muestras. $\mathrm{Si}$ bien existe intercambio de semillas entre las cuatro localidades en estudio, los genotipos muestran los efectos de la selección efectuada en cada localidad. Esto indica que, si el mercado es una referencia para las calidades del ajo que se comercializa, los productores finalmente imponen sus criterios de selección. Estos criterios no siempre son los mejores, ya que la selección de las semillas no brinda en todos los casos los resultados esperados en cuanto a rendimiento, calidad y resistencia a enfermedades; entre algunos aspectos, puesto que lo mejor de la producción se comercializa en detrimento de la calidad de la semilla que se aparta para la próxima siembra.

Los resultados derivados del presente estudio indican que la variabilidad inducida por la selección practicada por los productores es suficientemente amplia para ser utilizada en un programa de mejoramiento genético no convencional. Se aprecia un patrón de organización estructural bien definido, y que responde a la organización de los materiales genéticos como una función de la localidad donde se colectaron. Con esta información se puede formar una "Colección Núcleo", tomando muestras representativas puedan conservar in vitro, en un banco de germoplasma que además sea utilizado para proveer de material vegetal para un programa de mejoramiento.

\section{LITERATURA CITADA}

AL-ZAHIM, M; NEWBURY, HJ; LLOY-FORD, BV. 1997. Classification of genetic variation in garlic (Allium sativum L.) revealed by RAPD. Hortscience 32(6): 1102-1104.

CHEN, X.; SORIA, M.; YAN, G.; SUN, J; DUBCOVSKY, J. 2003. Development of Sequence Tagged Site and Cleaved Amplified Polymorphic Sequence Markers for Wheat Stripe Rust Resistance Gene Yr5. Crop Sci. 43:2058-2064.

DICE, LR. 1945. Measures of the amount of the ecologic association between species. Ecology 26:297-302.

GOWER, JC. 1966. Some distance properties of latent root and vector methods used in multivariate analysis. Biometrika 53:325-335.
GUZMÁN-MALDONADO, S.H.; MARTÍNEZ, O.; ACOSTA-GALLEGOS, J.A.; GUEVARA-LARA, F.; PAREDES-LÓPEZ, O. 2003. Putative quantitative trait loci for physical and chemical components of common bean. Crop Sci. 43:1029-1035

HERKLOTS, GA. 1972. Vegetables in south-east asia. Hong Kong. South China Morning Post Ltd. 525 p.

NEI, M; LI, WH. 1979. Mathematical model for studying genetic variation in terms of restriction endonucleases. Proc Natl. Acad. Sci. USA. 76: 5369-5273.

NOVÁK, F; HAVEL, L; DOLEZEL, J. 1982. In vitro breeding system of Allium. Plant Tissue Culture. In: Proceedings $5^{\text {th }}$ International Congress Plant Cell Tissue \& Cell Culture. Japón. P. 767-768.

PHILlIPS, W; RODRÍGUEZ, H; FRITZ, P. 1995. Marcadores de ADN: teoría, aplicaciones y protocolos de trabajo. Turrialba. Costa Rica. CATIE. 183 p.

ROSALES-LONGO, F.U. 1999. Mejoramiento genético de ajo egipcio por selección clonal individual. In: Informe técnico de resultados, 1999. Huehuetenango, Guatemala. Instituto de Ciencia y Tecnología Agrícolas. p 75-80.

SAMBROOK, J.; RUSSELL, D.W. 2001. Molecular cloning. 3ra. Edición. Cold Spring Harbor Laboratory Press. Nueva York. v 3 p. 6.61-6.62

SCHEAFFER, R.L.; MENDENHALL, W. OTT, L. 1986. Elementos de muestreo. Trad. G. Rendón; J.R. Gómez. México. Grupo Editorial Iberoamérica. 321 p.

SCHNELL, R.J.; BROWN, J.S.; OLANO, C.T.; POWER, E.J.; KROL, C.A. 2003. Evaluation of avocado germplasm using microsatellite markers. J. Amer. Soc. Hort. Sci. 128(6):881-889

SNEATH, P.H.A; SOKAL, R.R. 1973. Numerical taxonomy. Freeman, San Fancisco, EEUU. 573 p.

VOS, P.; HOGERS, R.; BLEEKER, M.; VAN DER LEE, T; HORNES, M.; FRIJTERS, A; POT, J.; PELEMAN, J.; KUIPER, M.; ZABEAU, M. 1995. AFLP: a new technique of DNA fingerprinting. Nucleic Acids Res. 23: 4407-4414.

WILKIE, S. 1997. Isolation of total genomic DNA. In: Clark, MS ed. Plant molecular biology: a laboratory manual. Berlin, Alemania. Springer Verlag. p. 1-25. 
